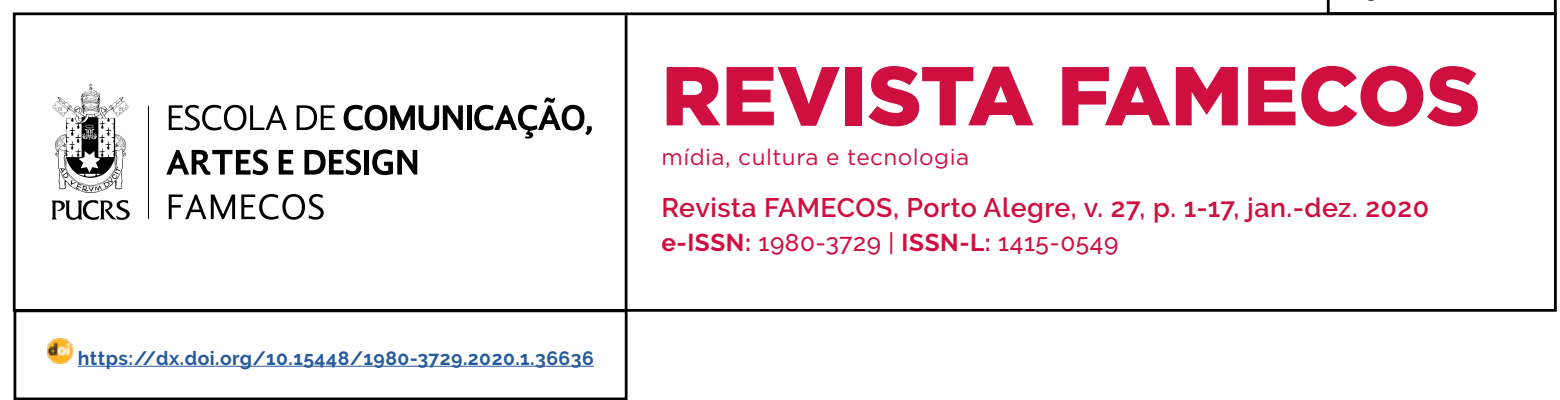

\title{
O objeto, o método e a metodologia na pesquisa da circulação e midiatização (inferências a partir da obra Ethnographie de l'exposition)
}

\author{
The object, method and methodology in circulation and midiatization research \\ (inferences from Ethnographie de l'exposition) \\ El objeto, el método y la metodología en la investigación de circulación y mediatización \\ (inferencias a partir de Ethnographie de l'exposition)
}

\author{
Jairo Getúlio Ferreira ${ }^{1}$ \\ orcid.org/0000-0002-4540-0572 \\ jferreira@unisinos.br
}

Recebido em: 11/12/2019.

Aprovado em: 17/4/2020.

Publicado em: 13/11/2020.

\section{(c) (1)}

Artigo está licenciado sob forma de uma licença Creative Commons Atribuição 4.0 Internacional.
Resumo: Este artigo desenvolve reflexões a partir da obra intitulada Ethnographie de l'exposition (VERÓN; LEVASSEUR, 1989). Essa escolha tem como referência nossa percepção sobre a riqueza do objeto, do método e da metodologia explícitos e implícitos nesse estudo para se pensar a linhagem de pesquisa-midiatização e processos sociais. A partir de nossas hipóteses de partida (primeira parte deste artigo), apresentamos a obra, de forma sistemática (segunda parte). Na terceira parte, desenvolvemos um conjunto de inferências singulares, tentando nos apropriar dessa investigação como um caso - estudo sobre um meio singular -, para inferências epistemológicas e metodológicas na perspectiva da midiatização e da circulação. Finalmente, apontamos questões sobre a relação entre a abordagem semioantropológica de Verón e os conceitos de campos sociais e de habitus em Bourdieu (apontando o horizonte dessa investigação em curso). ${ }^{2}$ Palavras-chave: Midiatização. Circulação. Epistemologia da comunicação.

Abstract: This article develops reflections based on the book entitled Ethnographie de l'exposition (VERÓN; LEVASSEUR, 1989). This choice is based on our perception of the richness of the object, method and methodology explicit and implicit in this study to think about the research lineage on mediatization and social processes. Based on our starting hypothesis (first part of this article), we present the work systematically (second part). In the third part, we develop a set of singular inferences, trying to appropriate this investigation as a case - study of a singular medium -, for epistemological and methodological inferences from the perspective of mediatization and circulation. Finally, we point out questions about the relationship between Verón's semio-anthropological approach and Bourdieu's concepts of social fields and habitus (within the framework of this ongoing research). Keywords: Mediatization. Circulation. Epistemology of communication.

Resumen: Este artículo desarrolla reflexiones a partir del trabajo titulado Ethnographie de l'exposition (VERÓN; LEVASSEUR, 1989). Esta elección se basa en nuestra percepción de la riqueza del objeto, método y metodología explícita e implicita en este estudio para pensar sobre el linaje de investigación de mediatización y los procesos sociales. Desde nuestras hipótesis iniciales (primera parte de este artículo), presentamos el trabajo sistemáticamente (segunda parte). En la tercera parte, desarrollamos un conjunto de inferencias singulares, tratando de apropiarnos de esta investigación como un caso de estudio de un medio singular para inferencias epistemológicas y metodológicas desde la perspectiva de la mediatización y la circulación. Finalmente, señalamos preguntas sobre la relación entre el enfoque semio-antropológico de Verón y los conceptos de Bourdieu de campos sociales y habitus (en el marco de esta investigación en curso).

Palabras clave: Mediatización. Circulación. Epistemología de la comunicación.

\footnotetext{
Universidade do Vale do Rio dos Sinos (Unisinos), São Leopoldo, RS, Brasil.

A investigação se refere às relações entre produção e reconhecimento, na perspectiva da midiatização, em interface com as teorias sociais e da linguagem.
} 


\section{Introdução}

Este artigo é parte de uma pesquisa sobre midiatização, circulação e reconhecimento. Nessa pesquisa, em curso, temos como objetivo estudos de interface entre a questão do reconhecimento na perspectiva da midiatização e a abordagem do reconhecimento em teorias sociais e da linguagem. O método de problematização se desenvolve nos seguintes direcionamentos: a) construção de interfaces epistemológicas onde hipóteses concorrentes são evidenciadas; b) investigação epistemológica visando a construção de inferências a partir desse espaço de interface; c) pesquisa empírica, onde se busca a configuração de hipóteses singulares, que considere inferências ascendentes.

A incomensurabilidade e o pluralismo metodológico (LACEY, 2012) são dificuldades essenciais que emergem nessas interfaces. O método abdutivo (FERREIRA, 2012) é central nesse momento do encaminhamento reflexivo, na medida em que supera (conserva, nega e eleva) as inferências dedutivas e indutivas presentes em cada uma das hipóteses mobilizadas. Trata-se, assim, não só de apresentar teorias e metodologias concorrentes, mas de buscar, de forma abdutiva, teorias e metodologias que possibilitem encaminhamentos de pesquisa empirica que superem as contradições observadas entre as hipóteses concorrentes.

As interfaces têm como "troco comum" a presença das teorias de Verón sobre o reconhecimento, a circulação e a midiatização. Como esse eixo, queremos manter o foco da pesquisa na área da comunicação, considerando-se que esse autor é um dos fundantes da linhagem de pesquisas em midiatização não só na América Latina, mas no mundo. Nesse sentido, as interfaces epistemológicas devem nos permitir enriquecer reflexões sobre o reconhecimento e a circulação, e as apropriações de aportes das teorias sociais e da linguagem pela área da comunicação, no âmbito da linhagem midiatização e dos processos sociais.

A construção de interface demanda a explicitação de cada uma das hipóteses, conforme suas teorizações, métodos e metodologias e casos singulares. Essa preliminar é uma via de aproximação necessária. Na busca de interface, consideramos produtivas inferências produzidas por autores em torno de observáveis compartilhados. Esse é o caso do museu e exposição, objeto de estudos em Verón (1982, 2013) e Bourdieu (1982, 1966). Esse encontro entre dois autores em torno desse observável facilita as inferências abdutivas (em torno das interfaces).

\section{Posição de fala (o que é midiatização)}

Em determinado momento, sugerimos a midiatização como relações e intersecções entre dispositivos midiáticos, "processos sociais" e "processos de comunicação" (FERREIRA, 2007). Essa formulação precisa ser especificada, incluindo suas interpenetrações matriciais:

a) os processos de comunicação se referem àquilo que pode ser observado como interações sociais, incluindo as possibilidades das conversações (versões, perversões, inversões e todas as variações do verso quando nas interações entre dois ou mais interlocutores - atores, organizações e instituições);

b) os dispositivos são construções sociais potenciais, resultantes das inovações dos meios (novos signos em suas materializações da experiência mental, em técnicas e tecnologias e simbólicas), quando essas se consolidam em usos, práticas e apropriações sociais. Portanto, meio e dispositivo não são coisas em si, mas objetos cujo significado é construído socialmente. Conservamos aqui o conceito de dispositivos com o qual trabalhamos há duas décadas (o meio como uma matriz semio-técnico-simbólica, conforme reflexão apresentada em 2006 - FERREIRA, 2007), mas ponderamos a validade do conceito somente para situações onde as práticas e as apropriações superam a tendência evanescente das inovações.

c) os processos sociais são relativos aos fluxos que podem ser observados entre a Eclésia, a Ágora e a Oikos, produzindo-se aí transformações das relações "entre" e "dentro" de cada uma dessas esferas (FERREIRA, 2017). Essas semânticas têm, preliminarmente, um sentido metafórico. Avançamos no sentido de uma definição conceitual e passamos a falar em campos, espaço público e espaço privado. 
Por interpenetração matricial nos referimos aos processos em que cada uma das dimensões aciona a outra, sucessivamente, de forma autopoiética e fractalizada. Interações-versões, meios-dispositivos e processos sociais se interpenetram.

A dificuldade situada nessas matrizes é definir a linha de corte sobre a genealogia da midiatização. É um fenômeno recente? Começa com o jornal? O livro? Em outro artigo (FERREIRA, 2018), chegamos a formular uma genealogia a partir do jornal e do livro. Esses, meios de conteúdo, em uma sucessão que passou pelos meios de programação (rádio e jornal) e os meios atuais (de indexação, interação e sistemas especialistas digitais). Mas, ao mesmo tempo, em busca de uma resposta a isso, começamos a desenvolver a perspectiva de que a midiatização é constitutiva da espécie, em uma abordagem epistemológica que acentua a proposição de semiose midiatizada. Essa semiose se caracteriza pela construção social de objetos-signos, materialidades, que deslocam a semiose da natureza, em especial a semiose do mundo vivo, vegetal e animal, pelos deslocamentos produzidos pelas interposições de objetos. Esses objetos são materializações da experiência mental. Esse processo é anterior à espécie humana, já presente na semiose animal (há materializações mentais em uma colmeia, formigueiro etc.). O que se desloca aí é o processo em que a semiose midiatizada da espécie se desdobra em formatos que superam os limites do tempo e do espaço definidos pelos rituais (eterna repetição das formas de objetivação), integrando-os a novas formas de operações concretas e formais que possibilitam novas gestões dos territórios naturais e, também, a desterritorialização natural.

Acreditamos que essa perspectiva é convergente com Verón e Levasseur (1989): a midiatização é, antes de tudo, a materialização em meios da experiência mental. Caracteriza, portanto, a gênese antropológica da espécie (VERÓN, 2014). Essa formulação é assumida por nós como mais completa, e a adotamos como referência central para pensarmos a midiatização, sem negar as matrizes acima.
Por quê? Basicamente, em nossa formulação, porque nos permite pensar uma linha de corte ontológica que é também epistemológica: o deslocamento da semiose da natureza para a semiose social. Esse deslocamento é fundado pela espécie, por suas características bio-psico-cognitivas. A principal diferenciação que se funda aí é a capacidade inferencial que se singulariza relativamente a outras espécies, que já desenvolviam e desenvolvem capacidade de materialização da experiência mental. A semiose midiatizada se refere a esse processo em que a materialização da experiência mental em objetos é, imediatamente, base para novas inferências individuais e sociais, referência das interações, fomento de interpretação de indicios e imaginários. Evidentemente, pensar a genealogia da midiatização nessa perspectiva é muito mais complexo.

Isso não quer dizer que toda experiência mental possa ser objetivada. ${ }^{3} \mathrm{~A}$ formulação é quântica: se nem tudo é matéria, há, em nosso cosmo-planeta e no mundo social, muito de energia não materializada. Portanto, a midiatização é um universo restrito, mesmo quando falamos da semiose midiatizada. Há um universo energético que, como halo, nos aciona. Esse é de difícil acesso, inclusive porque não materializado. Além disso, há um (imenso) universo de sentidos que são imaginários e simbólicas, conscientes, subconscientes e inconscientes, que não se manifestam materialmente.

O fato de que o amadurecimento reflexivo (epistemológico) da espécie só tenha tomado consciência dessa relação no contemporâneo, a partir das realizações em meios como o livro, o jornal, o rádio, a televisão e nas redes. Trata-se, aqui, da perspectiva histórico-dialética (não evolucionista) de que o contemporâneo revela contradições do passado. Assim, para Marx (MARX, 2011, p. 58), a compreensão da lei do valor só é possível no capitalismo, quando essa se revela como fenômeno observável - realizada não apenas na esfera mercantil (comércio), mas também na esfera da produção industrial. Por analogia, a midiatização só é passivel de tomada

\footnotetext{
3 Aqui, é importante destacar as reflexões de João Damásio (doutorando) apresentadas em Seminário de tese da Linha Pesquisa 4 Midiatização e Processos Sociais, no PPGCC-Unisinos, São Leopoldo, em novembro de 2019.
} 
de consciência com a emergência dos meios no século XX (em especial, com as inovações materializadas no rádio, na televisão e no cinema).

Porém, a investigação empírica na linhagem não abrange todas as formas de materialização da experiência mental. Seu objeto está recortado: somente aquilo que está ou irrompe no espaço público, por ações de indivíduos ou atores localizados no espaço privado ou no espaço dos campos de especialistas, é passivel de investigação empírica da midiatização histórica e antropológica. Um imenso universo de signos materiais construidos pela espécie está restrito ao universo privado ou de campos especialistas, que se diferenciam e definem regras de acesso. São objetos potenciais. Estão guardados em cofres sociais e psicológicos de diversos niveis. Antes da irrupção no espaço público a semiose midiatizada é potencial.

Porém, nos três casos (materialidades do espaço privado, dos campos especialistas e imaginários e das simbólicas não manifestas) algo pode irromper no espaço público. Nesse processo, os meios disponiveis em espaços públicos são centrais para a compreensão dos processos midiáticos e, como forma de olhar, à midiatização. Essa é a força específica desses meios de publicização (livro, jornal, rádio, televisão etc.), pois aceleram os processos de circulação das materializações em signo das experiências mentais da espécie. Trata-se de um processo de circulação entre o imaginário, as operações cognitivas e as condensações simbólicas, materializadas em um "real" disponivel no espaço público. Isso pode então ser observado e analisado na perspectiva da semiose. Não se trata da semiótica enquanto lógica, mas de lógicas que estão em processos, a partir de acessos, utilizações, usos, práticas e apropriações sociais.

Em termos categoriais, os processos midiáticos podem ser diferenciados no que acionam em termos de:4

a) diferenciação e integração;

b) conectividade, ubiquidade e omnipresença; c) inovação, profecias e frustrações;

d) aldeamento, ampliação da escala e reformulação dos territórios;

e) adaptação, regulação, ritmos e irrupções;

f) reconstrução do tempo e espaço.

Nas inferências finais deste artigo, refletimos também a partir dessas categorias acima como heuristicas para análise da midiatização conforme os meios em estudo.

Acreditamos que essa perspectiva epistemológica autoriza, retroativamente, pensar inclusive a exposição (e o museu) como meios midiáticos. É nessa perspectiva ampla que situamos o estudo anterior de Verón e Levasseur (1989), como uma investigação empírica (ou caso) construida no âmbito da linha de pesquisa que intitulamos midiatização e processos sociais.

Nesse estudo, os autores investigam o que nominam como estratégias de visitação. A exposição como meio midiático antecipa uma abrangência dos objetos de investigação sobre a midiatização. É como se a obra antecipasse a concepção antropológica de Verón sobre a midiatização, décadas antes de sua formulação explicitada nesta década. Ao ampliar os meios passiveis de investigação enquanto midiatização até a exposição e, depois, ao validar isso epistemologicamente, Verón, em nossa percepção, abre um amplissimo leque de estudos - a midiatização abrangendo toda e qualquer forma de materialização da experiência mental, onde o que especifica o objeto é a circulação, entendida como relações entre as lógicas de produção e as lógicas de recepção dessas materialidades (meio). Ou seja, o foco epistemológico na forma de olhar é a circulação, teórica e metodologicamente situada em materialidades - formato central, em suas perspectivas, para investigação empírica na perspectiva da midiatização.

A circulação remete à análise do que nominamos como semiose midiatizada que irrompe ou está no espaço público. Portanto, assim como nem toda experiência mental é materializada, e

4 Parte dessas caracteristicas foram acentuadas na conferência de Andreas Hepp, no III Seminário Internacional de Pesquisas em Midiatização e Processos Sociais, na Unisinos, em São Leopoldo, RS, em maio de 2019. A ampliação da escala é uma dimensão sempre acentuada por Verón. 
nem toda materialização da experiência mental ingressa no fluxo entre os espaços privados, públicos e campos de especialistas, a midiatização só tem como objeto analisável em termos de circulação as materialidades acessiveis. Isso é, não se trata aqui de um materialismo plano. Essas materializações se constituem, no espaço social, em base para novas inferências, desde os niveis mais simples dos acessos e dos usos até os mais duradouros (incorporação às práticas) e complexos (apropriações), constituindo-se, nessas passagens, novos imaginários que podem retroagir em formato de novas rotinas e lógicas de produção, que voltam a se materializar em novos meios-objetos, disponiveis nos espaços privados, públicos e de campos especialistas para acesso, usos etc. $O$ ciclo é interminável. A análise da circulação se "esforça" para compreender as lógicas desse ciclo.

Essa perspectiva converge e se diferencia da abordagem de Fausto Neto (2008). Converge quando foca no conceito de circulação como operador cognitivo para análise de processos midiáticos. Diverge quando não diferencia sociedade dos meios e sociedade midiatizada. Em nossa perspectiva, a midiatização está na origem da própria espécie, quando essa se diferencia da natureza e de outras espécies vivas, ao se materializar em meios desde as suas origens (em suas várias eras, há milhões de anos, como destaca Verón [2014]), acionando aí a semiose social da espécie. Nesse sentido, a midiatização abrange, mas não se restringe, também a sociedade mercantil - como situa Bernard Miége et al. (2016) - ou a institucionalização dos novos meios (HJARVARD, 2015). Essa temporalização da midiatização (na sociedade mercantil; na institucionalização dos meios; na diferenciação entre sociedade dos meios e sociedade midiatizada) pode ser muito interessante para demarcar a historicidade da midiatização, desde os meios objetivados na pré-história. Isso demanda reflexões futuras.

Nessa perspectiva, nossa formulação é que a midiatização é uma teoria social focada na semiose midiatizada, que não pretende subsumir as formas de inteligibilidade de economias especificas da cultura, da economia e da política, mas sugere aos diversos saberes no campo das ciências sociais e da linguagem novas percepções e hipóteses.

\section{A exposição na perspectiva da midiatização}

A reflexão sobre Etnografia da exposição (VERÓN; LEVASSEUR, 1989) tem como referência, primeiramente, a nossa percepção da riqueza do objeto, do método e da metodologia explícitos e implícitos nesse estudo. Mas é importante também destacar que Verón o cita em seu trabalho conclusivo (Semiose II, onde desenvolve reflexão sobre a pesquisa realizada quatro décadas antes, ocupando, para isso, um capítulo de 35 páginas - uma das principais pesquisas na terceira parte da obra, sobre a circulação), mas também em trabalhos anteriores. Esse destaque à obra é inquestionável, por seus aspectos fundantes, em termos de pesquisa empírica. Apesar dessa importância, não tem recebido, nas investigações sobre a circulação, o devido reconhecimento (o que se manifesta em um número de citações muito reduzido). Parte disso pode decorrer da ausência de oferta dessa obra em português, e parte ao próprio fato de que o objeto sugerido para estudo da midiatização (a exposição) desconstrói muitas leituras feitas por seus "seguidores".

As principais contribuições dessa investigação são, em nossa percepção: a localização da exposição como meio midiático e, a partir disso, passivel de investigação na perspectiva da circulação; o uso efetivo do método semiótico como referência da construção do caso de investigação; e a articulação original na lida metodológica, articulando análise semiótica, observação etnográfica, entrevistas e dados estatísticos.

A adesão ao campo da comunicação é clara. Verón integra, em sua investigação, a perspectiva antropológica, em especial a etnografia - aporte reconhecido na área para estudo de interações entre indivíduos e desses com os meios sociais construídos (objetos materiais). As analogias possiveis, a partir disso, se ampliam às interações dos indivíduos com os objetos midiáticos que estão canonizados na área (jornal, rádio, televisão, meios digitais). Cada um desses meios têm singularidades, e a generalização obscurece, em parte, o 
que têm em comum. É necessário reconhecer a validade da hipótese de que a midiatização sofre mutações, conforme as objetivações em meios. Os usos sociais à jusante dessas objetivações, configurando circuitos de interação, são então passiveis de análise na perspectiva da circulação, para se entender esse processo como parte de uma historicidade e atualidade do que chamamos de midiático. No contexto desses processos, os meios, quando consolidados em práticas e apropriações, podem ser condensados em dispositivos. O dispositivo, nesse sentido, não se refere ao uso efêmero dos meios, das objetivações, mas àquilo que se conserva, enquanto agenciamento.

Em Etnografia da Exposição (1989), Verón e Levasseur investigam trajetórias possiveis de percurso em uma exposição. Em termos de método (e isso nos parece essencial em seus estudos), os autores mobilizam hipóteses de Verón sobre a midiatização, considerando a singularidade do objeto. A partir dessas hipóteses, fazem uma imersão dedutiva, em que novas descobertas são realizadas (ampliando a hipótese inicial), as quais se constituem em base para hipóteses de chegada sobre a exposição. Esse método tem validade transversal, ou seja, corresponde a uma lógica que pode ser acionada na prática de pesquisa.

A hipótese de base responde às perguntas sobre as relações entre as formas da exposição (disposição das obras) como proposição de sentido e aquilo que está em negociação de sentido, pelos visitantes, que realizam "apropriações" em combinatórias diversas. Os autores refletem sobre o que são "mídias". Para fundamentar a localização da exposição como "mídia", a diferenciam dos "mass-mídias". O comum entre os dois (o genérico e o específico) é a escala de acesso e de usos potenciais. O que caracteriza uma "mídia" em geral é o acesso público, em diversos niveis qualitativos, de uma mesma mensagem ou conjunto de mensagens, em oposição ao acesso estritamente privado. Assim, o que caracteriza um meio midiático, em geral, ou massivo, em particular, é a forma de uso social (público ou privado). Isso será retomado depois, em seus esquemas sobre a midiatização. Essa linha de corte é importante.
Se retomamos a hipótese que sugerimos sobre a midiatização como materialização da experiência mental, os objetos das pesquisas empíricas são aqueles que estão disponibilizados no espaço público, acionados a partir de campos de especialistas e/ou do mundo privado.

Verón (1989) destaca que o termo mensagem, em sua formulação, não se refere a conteúdo, pois sua ocorrência se refere a um sentido em negociação, derivada das tensões entre produção e recepção, ou entre conhecimento e reconhecimento. Ou seja, inscrito na circulação, o signo ultrapassa os conteúdos, o que significa que a mensagem não se reduz a conteúdos manifestos. Os "mídias", afirmam Verón e Levasseur (1989), desenvolvem diversas operações, que podem ser traduzidas em três categorias de signos (ícones, indices e interpretantes), inclusive se diferenciando como "mídias" conforme as operações de produção/conhecimento acionadas para as materializações que disponibilizam em espaço público. Mas as estratégias de visitação não respondem de forma linear a essas proposições. Ou seja, a questão central investigada em "Etnografia da Exposição" remete às relações entre operações de produção e operações de reconhecimento, sobre as quais acentua a não linearidade, observada como diferença (defasagens) entre as operações nos dois polos. Nesse sentido, a análise do signo, propõem, tem que ser situada na interdiscursividade - ao contrário do que sugere a semiótica que pretende uma análise do signo isolado das operações de sua produção e reconhecimento.

\section{O diagrama-caso (a hipótese de partida): a circulação como foco da pesquisa em midiatização}

O diagrama sobre este processo informa que a organização espacial de distribuição das obras expostas é uma classe de discursos que será acessada e apropriada conforme operações de reconhecimento (Quadro 1). 
Quadro 1 - Esquema sobre a circulação - adaptação do modelo de circulação conforme Verón

\begin{tabular}{|c|c|c|c|c|}
\hline \multicolumn{3}{|c|}{ OPERAÇÕES DE PRODUÇÃO } & & \\
\hline & & $\begin{array}{c}\text { DISCURSOS } \\
\text { SOCIAIS } \\
\downarrow\end{array}$ & & \\
\hline & & \multicolumn{3}{|c|}{ OPERAÇÕES DE RECONHECIMENTO } \\
\hline $\begin{array}{l}\text { Exposição temá- } \\
\text { tica em oposição } \\
\text { a obra isolada } \longrightarrow\end{array}$ & $\begin{array}{l}\text { Lógicas concei- } \\
\text { tuais do tema/ } \\
\text { do espaço } \rightarrow\end{array}$ & $\begin{array}{l}\text { Disposição5 (mise } \\
\text { en espace) passí- } \\
\text { vel de análise }\end{array}$ & $\begin{array}{l}\text { Modos de } \\
\text { apropriação } \\
\leftarrow\end{array}$ & $\begin{array}{l}\text { Modelos de visitante (motiva- } \\
\text { ções, capital cultural, relação } \\
\text { com o saber, etc.). } \\
\leftarrow\end{array}$ \\
\hline & & $\stackrel{\uparrow}{\uparrow}$ & & \\
\hline
\end{tabular}

Fonte: Verón e Levasseur (1989, p. 31).

Conforme o esquema do Quadro 1, a pesquisa da circulação demanda a reflexão sobre as articulações, no caso em investigação (exposição), de diversas dimensões, entre as quais destacamos:

a) a conceitualização e a disposição do tema conforme o espaço da exposição, materializada em textos, imagens, materiais, combinados ou não (os objetos a serem visitados). Aqui a ordem metonímica (direita/esquerda; visivel/escondido; alto/baixo; próximo/distante etc.) também é objeto de operações;

b) a disposição como discurso (e suas classes: pedagógico; histórico; estético etc.) social;

c) o contexto social maior e especifico;

d) os modos de apropriação do visitante também contextualizados por capitais culturais, relações com o saber estético, motivações). Destacamos, aqui, para o nosso objeto de interface, a semântica reunida no termo "capitais culturais".

\section{As lógicas de produção e da exposição}

Para realizar a análise conforme essas dimensões, Verón e Levasseur (1989) encaminham uma metodologia complexa e abrangente: a) documentos sobre a exposição e a reunião com os curadores da exposição; b) realização de um apanhado fotográfico exaustivo sobre a exposi- ção; c) análise da exposição (articulação entre obra e espaço); d) etnografia do comportamento dos visitantes; e) entrevistas com os visitantes.

A exposição sugere como objetivo incentivar a reflexão sobre as férias na França, de 1860 a 1982, considerando a temática em seu passado e momento contemporâneo. A série histórica está documentada em fotografias. Os autores apontam problemas nas relações entre historicização e formas de registro (branco versus preto para o passado versus coloridos para o presente; "fotos artísticas" versus "fotos realistas"; fotos em papel versus fotos em slides; em diversas oposições do signo marcando a oposição histórico versus contemporâneo).

A principal problematização critica se refere à analogia entre arte, papel e cores em branco e preto, de um lado, e realismo, colorido e slide, de outro. A primeira como representação do que é histórico; a segunda, do que é contemporâneo. Acentuam, nisso, a conexão das epistemologias da arte (para o histórico) versus aquelas das ciências sociais e da psicologia (para o contemporâneo), apresentadas em textos adjuntos às imagens expostas. A crítica a essa oposição é um fio condutor na leitura dos documentos e dos agenciamentos do espaço. Aparece, aí, um processo de análise que será permanente em Verón: a análise das operações, materializadas em meios, na perspectiva semiótica. 
Os autores definem a visita ideal como aquela que está em conformidade com a lógica da produção (chamamos de lógica, e não gramática, no decorrer deste texto). A produção, sem dúvida, sugere um percurso de visitação do museu. Esse percurso, como informado, é estudado a partir dos documentos e do espaço, considerando-se especialmente a distribuição das obras (fotografias e textos) nesse espaço. Essa distribuição responde a uma genealogia das "férias" conforme as fotografias listadas acima. Os autores intitulam isso "estrutura de conjunto". À esquerda, um corredor (A - de 1860 a 1945 e B - 1936 a 1945) onde estão os primeiros periodos históricos (até 1945). No centro, um quiosque, onde se encontram os slides, com o presente (1946 a 1982). Nos três espaços designados como vitrines $(P)$, há manequins vestidos de roupas de férias correspondentes aos tempos históricos ( $\mathrm{A}$ e B) e atual (B). No fundo, uma pintura, em mural, evocando as férias (ver Figura 1).

Figura 1 - O espaço

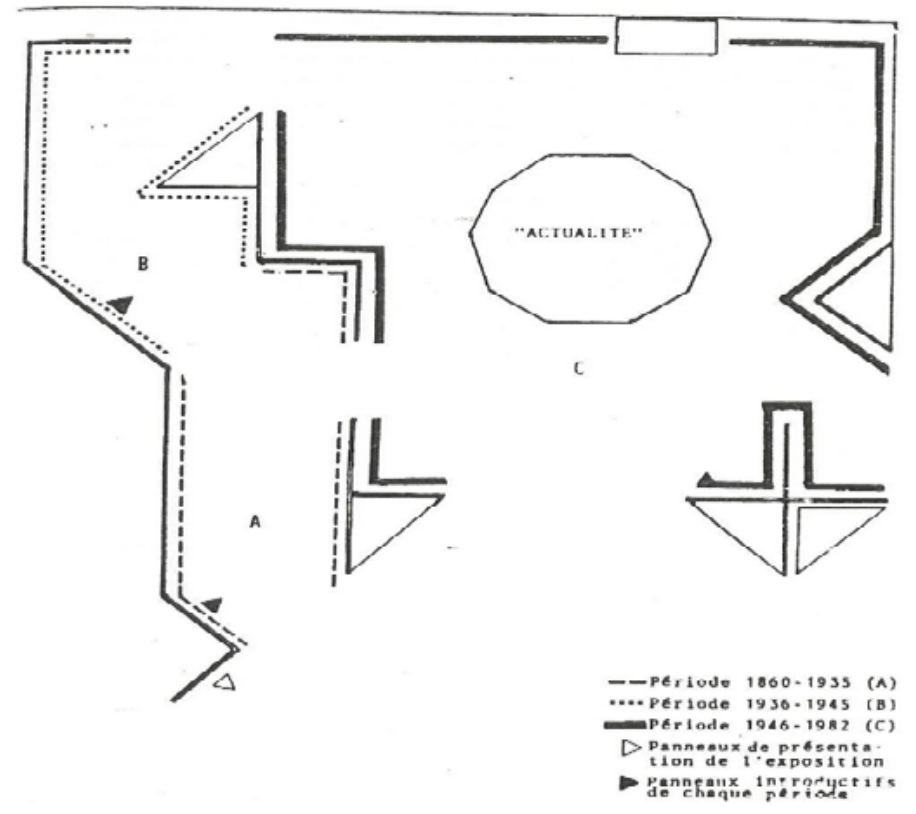

Fonte: Verón e Levasseur (1989, p. 25).

A reflexão dos autores se dirige, então, aos percursos possiveis. Conforme o espaço da Figura 1 , há o percurso histórico, em que o visitante segue conforme a cronologia proposta, em sucessão de imagens, textos e estatísticas. Mas há também outro percurso, em que o visitante começa pelo quiosque, o que significa começar a visitação pelo presente.

Como a visita pode ocorrer? Os autores falam então em um "núcleo decisional", que direciona possibilidades de visitação, no conjunto de todas as possibilidades de deslocamento do visitante. O deslocamento em cada uma das camadas do espaço considera esses núcleos, sucessivos, no percurso adotado, e possibilidades de acesso a outros etc. A visitação, entretanto, não é, obrigatoriamente, a todas as unidades (camadas) possiveis. Isso é diagramado como exposto na Figura 2.
Figura 2 - Possibilidades de visitação

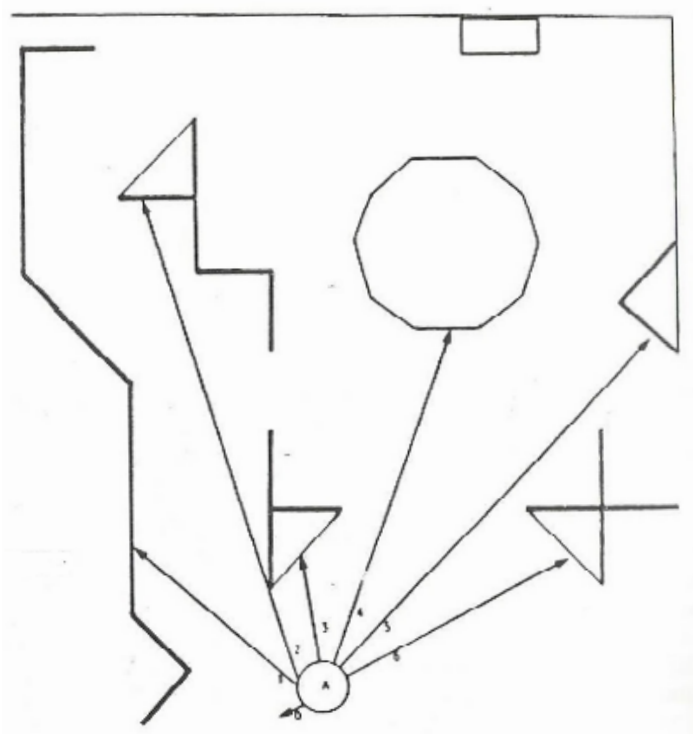

Fonte: Verón e Levasseur (1989, p. 27). 
Conforme o ponto a que chega o visitante, em seu deslocamento, novas decisões devem ser tomadas, a partir de suas percepções no contexto de "núcleos decisionais" e novas possibilidades, em termos de ingresso em outras "camadas" do museu (ver Figura 3).

Figura 3 - Possibilidades de visitação
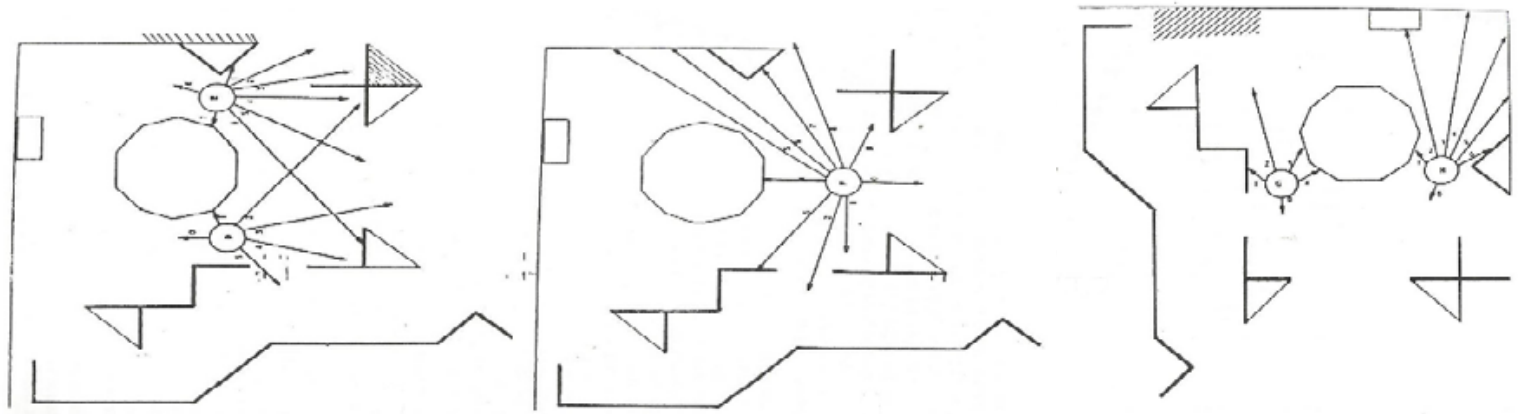

Fonte: Verón e Levasseur (1989, p. 28).

Na perspectiva dos autores, as escolhas não são definidas, em si, pelas possibilidades do espaço, nem pelos núcleos decisionais e, inclusive, pelas restrições de acesso e de direcionamentos desses acessos. $O$ central das escolhas são as estratégias dos visitantes, ou seja, o que eles buscam naquele espaço de possibilidades. Entretanto, o visitante ideal ("o bom visitante") é aquele que se desloca conforme a proposta da produção da exposição - ou seja, seguindo o percurso histórico sugerido. Esse percurso é então numerado pelos autores.

A visitação, no contexto campo de possibilidades, é referida como estratégica. Essa, entretanto, não se define apenas pela distribuição no espaço. O "bom corpo visitante" é aquele que se deixa levar pela progressividade, inteligibilidade e estruturação da exposição, acompanhando a lógica (semiótica) dos registros, que aciona as dimensões estéticas (das imagens) e racionais (dos textos histórico-sociológicos), em tensão com as imagens banalizadas dispostas no quiosque.

\section{As lógicas dos visitantes}

Durante quatro semanas, os pesquisadores observam o comportamento dos visitantes, em diversos turnos e dias da semana, utilizando câmeras de vídeo no espaço da mesma. Por saturação, observam que as visitas correspondem a quatro tipos, ou a uma combinatória de duas das alternativas identificadas, designadas metaforicamente: formiga, gafanhoto, borboleta e peixe. As "gramáticas" são apresentadas de forma descritiva e, também, em diagramas, relativos a cada uma das figuras. Essas quatro metáforas podem ser assim resumidas (VERON; LEVASSEUR, 1989; MARIANI-ROUSSET, 2008, p. 34):

Figura 4 - Percursos de visita em Verón e Levasseur $(1989)^{6}$
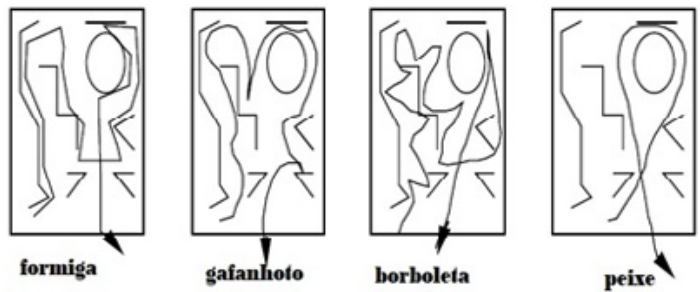

Fonte: Mariani-Rousset (2008, p. 34).

Os esquemas da Figura 4, conforme os pesquisadores, correspondem às seguintes caracterizações das quatro formas de visitação:

a) A formiga, designada visita proximal pela proximidade dos visitantes aos painéis, com um tempo longo de permanência (em torno de 20 minutos), com paradas máximas (cerca de 20), acompanhando da mesma forma os diferentes espaços, seguindo a lógica linear sugerida pelas "gramáticas de produção" (Figura 5). 
Figura 5 - Percurso metaforizado como formiga

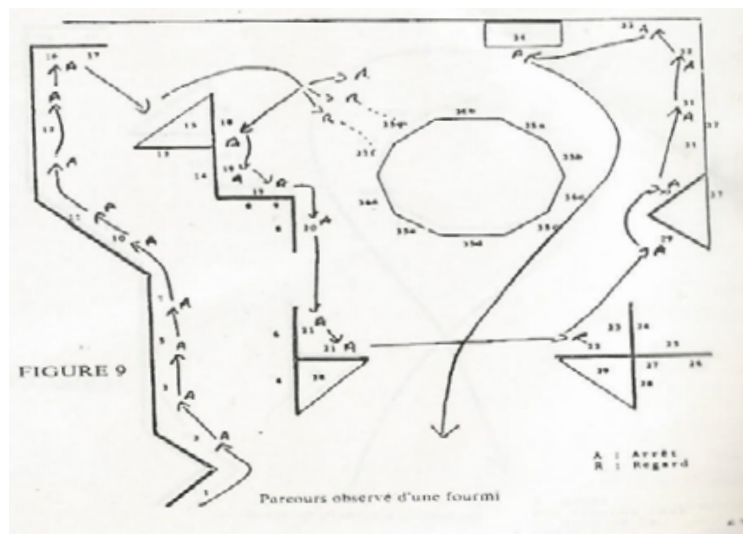

Fonte: Verón e Levasseur (1989, p. 33).

b) O gafanhoto (visita punctum) faz uma visita curta (cinco minutos, com poucas paradas em torno de cinco também - e pouco tempo em cada ponto). Ele se dirige a pontos de interesse, com passagens por espaços vazios, sem seguir a ordem cronológica. 0 esquema indica uma visita rápida (Figura 8).

Figura 8 - Percurso metaforizado como gafanhoto

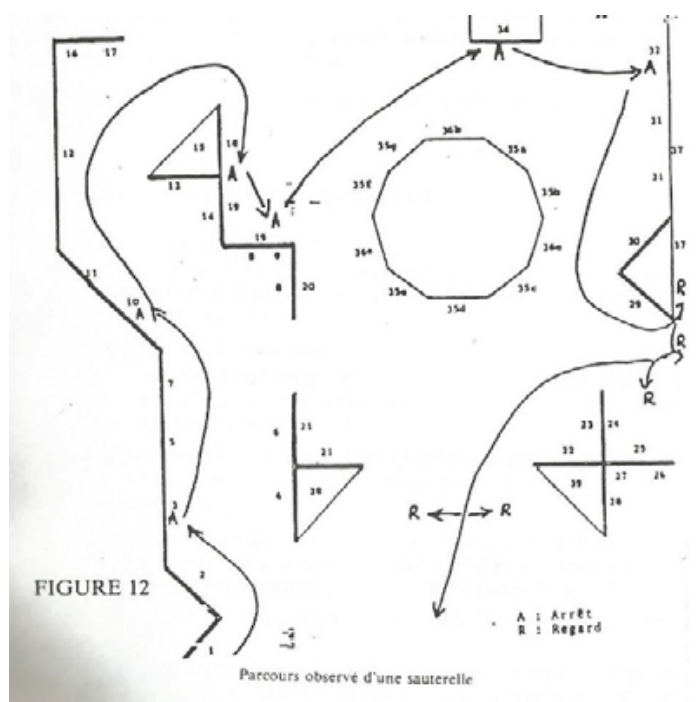

Fonte: Verón e Levasseur (1989, p. 35).

b) A borboleta (visita pendular, em zigue-zague, em movimentos à esquerda e à direta, de forma pendular) tem uma forte ligação com objetos culturais: este visitante sabe o que veio olhar. Com um tempo de visita em média de 15 minutos e 15 paradas, escolhe obras a "visitar", evitando espaços vazios. Segue a ordem cronológica, mas com escolhas (Figura 6).
Figura 6 - Percurso metaforizado como borboleta

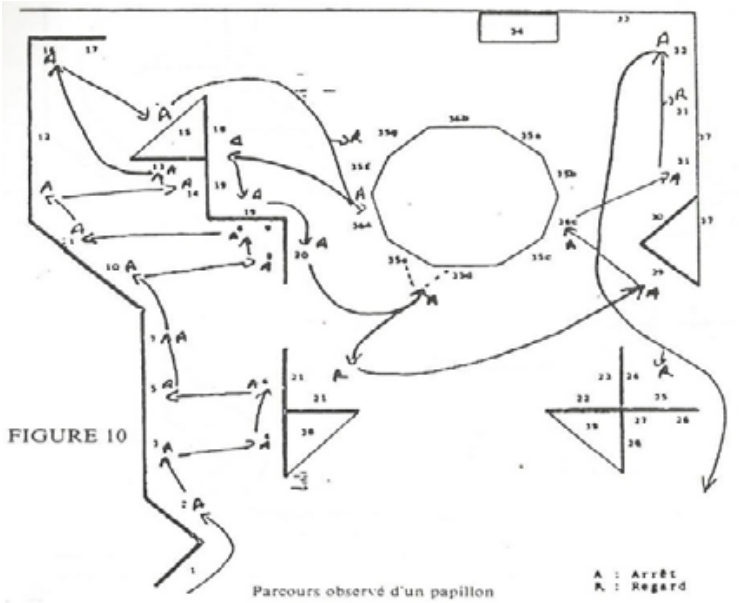

Fonte: Verón e Levasseur (1989, p. 34).

c) O peixe (deslize de visita) é muito pouco motivado, "em retirada", como fazem os peixes quando tentamos pegá-los. Não se fixam em um ponto. Ele "passa", cruza a exposição. Ele tem um tempo de visita curto (5-10 minutos), olha para os objetos à distância e não para. É indiferente à ordem cronológica sugerida. O esquema é claro em informar que se trata de uma visitação "mais superficial" (Figura 7).

Figura 7 - Percurso metaforizado como peixe

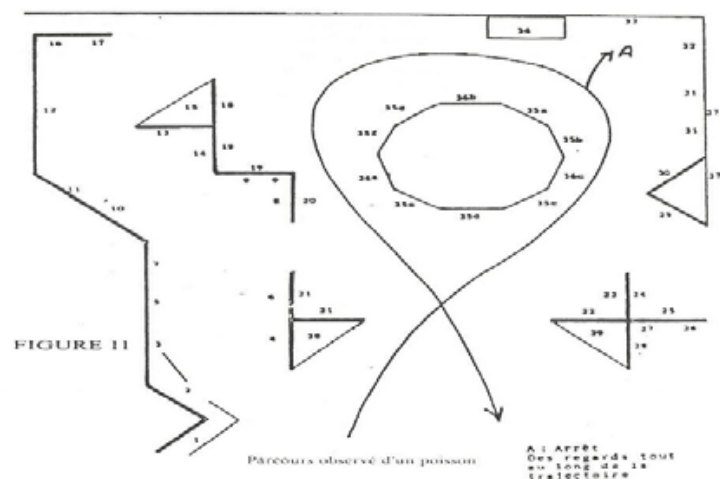

Fonte: Verón e Levasseur (1989, p. 34).

Em Semiosis Social II (VERÓN, 2013), o autor destaca que as trajetórias investigadas são fenômenos que manifestam processos cognitivos gerais, relativos a deslocamentos dos corpos nos espaços. Manifesta-se aí, diz o autor, o corpo como operador de primeiridade (afetos, percepções e intuições), que ocorre na esfera dos acessos e dos usos dos meios, enquanto reco- 
nhecimento. A investigação sobre a exposição é, nesse sentido, um primeiro estudo empírico de Verón sobre uma problematização epistemológica que já havia trabalhado teoricamente. Situa-se, nessa esfera, a primeiridade perante ofertas de objetos (fotografias e espaço da exposição) que são tentativamente regulados com normas de visitação (incluindo a sequência sugerida de visitação, em discursos sobre a exposição, incluindo as fotografias como objeto do discurso). Nesta obra o autor apresenta a inferência que acompanha a sua investigação sobre o reconhecimento:

A defasagem produção e reconhecimento como um processo de decomposição/recomposição, anulação/ativação, desconstrução/reconstrução, das trajetórias propostas pelo enunciador, e sua inserção em uma rede de trajetórias qualitativamente diferentes (VERÓN, 2013, p. 321-322).

Nessa investigação, o autor destaca que o objeto não é a busca de uma tipologia de atores sociais ou de variações psicológicas deles, objetos da sociologia e psicologia. Porém, coloca a questão sobre a coerência ou incoerência geral dos mundos mentais dos atores, o que demandaria reflexões sobre os sistemas sociais, para além dos sistemas (mentais) individuais. Como é relativamente conhecido, Verón fará isso, em outros escritos, a partir de Luhmann.

Entretanto, nosso esforço aproximativo neste artigo, sugere um outro caminho, um deslocamento, buscando a reflexão sobre esses sistemas sociais em Bourdieu. O desafio epistemológico é forte, pois se trata de evidenciar, a partir da obra desse autor, o conceito de sistema como âncora possivel no âmbito de suas formulações centrais (habitus e campos sociais). Essa possibilidade, em nossa percepção, está facilitada pela mobilização desse operador semântico (sistema) em toda a sua obra, em especial, nos esquemas sobre a circulação apresentados em La Distincion (BOURDIEU, 2000). Com esse deslocamento, não pretendemos "demonstrar" superioridade epistemológica de Bourdieu em relação a Luhmann. Trata-se, de forma mais simples, de explorar outros direcionamentos nas interfaces necessárias às investigações sobre o reconhecimento quando se pensa a circulação - como relação entre produção e recepção.

\section{Entrevistas}

Após identificar as figuras acima, os pesquisadores realizaram 25 entrevistas semidiretivas, sendo assegurado, por imagens gravadas, o percurso de visitação dos entrevistados. As entrevistas foram organizadas em quatro partes.

A primeira parte é relativa a:

a) relação com o museu específico. O objetivo é explorar o imaginário sobre esse espaço investigado como "espaço de cultura" (identificando frequência de visitas; lugares visitados; imagens e representações associadas);

b) motivação da visita. Aqui, não se trata da relação com o lugar da exposição em geral, mas especificamente com "esta" exposição;

c) mecanismos de decisão de visitar. Isso se refere a motivações precisas sobre a visita. Se ocorreu planejadamente ou por acaso, se tem noção do que visitou, suas percepções entre o título da exposição e seus "conteúdos". Enfim, relatos sobre a exposição por parte do "receptor", visando aferir o conhecimento, por parte do entrevistado, sobre a mesma.

A segunda parte é relativa a:

a) visitação em si. O receptor deve relatar os pontos visitados, as paradas, mudanças de trajetória, omissões, etc., comentando os diferentes "elementos" de cada ponto e percurso.

A terceira parte é relativa a:

b) o percurso, a exposição e o museu, confrontados, agora, com as imagens de seus percursos e de outros visitantes. Retornase assim às questões gerais e específicas sobre a exposição, sobre comportamentos de visitação. Essa última parte, conforme os pesquisadores, não agregou nenhuma hipótese adicional.

A partir dessas entrevistas, os autores apresentam (VERÓN; LEVASSEUR, 1989, p. 37-49) as motivações, estratégias e imaginários na forma de fragmentos, que compreendemos como materiais e indícios que reforçam suas inferências a partir dos percursos, especificando e possibilitando-se aí novas inferências pontuais, ampliativas. Isso é feito em cada agrupamento (figuras apresentadas em seção anterior). 


\section{Inferências transversais}

As conclusões (com o título A propósito dos modos de apropriação de Férias na França e esta pesquisa) apresentam inferências que consideramos transversais. Destacam a "importância" da distinção entre produção e reconhecimento na análise dos meios, em que o segundo não é dedutivel da primeira. Aqui, sublinhamos a diferenciação entre a análise que acentua a estrutura do discurso e a proposta dos autores, de focar na circulação. Mesmo considerando a importância desse momento da análise (a estrutura do discurso), a mesma, na perspectiva da circulação, deve ser colocada em relação com as formas de reconhecimento - investigadas por eles enquanto estratégias de visitação. Essa relação funda, conforme os autores, uma nova hipótese sobre os "efeitos das mídias", a qual deve considerar a especificidade dos meios investigados, as propriedades dos discursos desses meios e formas de reconhecimento - relação.

A pesquisa, em termos de método, parte de uma hipótese referenciada na interface entre a semiótica e uma perspectiva de socioanálise, metodologicamente etnográfica. Descobre-se pela ampliação dessa hipótese, especificando-a e singularizando-a conforme as inferências que configuram o caso (a exposição sobre as Férias na França, em um museu especifico).

As inferências finais relativas às figuras acen- tuam que as visitas são matizadas por capitais culturais em diversos niveis. Há duas que, inferem, tenderiam a ter o mesmo comportamento em outras exposições: a) a visita tipo borboleta, que se faz com conhecimento do tema; e b) a visita tipo formiga, que se faz por conhecimento do local de exposição, pedagogicamente passiva, disposta a aprender, de forma "doce". Há duas outras em que a negociação de sentido com os objetos culturais expostos tem pontos de ruptura, mesmo que esses sejam diferenciados: a) a visita tipo peixe, que se comporta como se fosse um turista, ou alguém que passa olhando uma vitrine, ou vendo monumentos históricos, sem conhecer os seus contextos; b) e, finalmente, a visita tipo gafanhoto, marcada por uma subjetividade, em que a relação com o objeto cultural exposto ocorre conforme ressonâncias, como se flanasse, desarticulado com a proposta do espaço.

Os autores apresentam, então, diagramas conclusivos do caso. Esses diagramas desdobram as inferências apresentadas textualmente, mas permitem sistematizar as inferências ampliativas, inclusive por um tipo de sistematização das inferências em que os autores permitem ao leitor comparar, por analogias, as quatro formas de visitação expostas.

Desses diagramas, acentuando alguns elementos, subtraímos o esquema do Quadro 2, comparando os comportamentos etnografados:

Quadro 2 - Comportamentos etnografados

\begin{tabular}{|c|c|c|c|c|c|}
\hline & Capitais Culturais & Negociação & Objeto & Especificidade & Corpos \\
\hline Borboleta & Maestria & Cultural & Tema & Plano de Visita & Livres \\
\hline Formiga & Atento & Cultural & Espaço & Pedagógico & Demanda Orientação \\
\hline Peixe & Desconfiado & Em retirada & Ausente & Procura do Objeto & Turístico \\
\hline Gafanhoto & Novato & Subjetiva & Ausente & $\begin{array}{c}\text { Procura de Frag- } \\
\text { mentos }\end{array}$ & $\begin{array}{c}\text { Assimilação Defor- } \\
\text { mante }\end{array}$ \\
\hline
\end{tabular}

Fonte: Autor (2019). 


\section{Conclusões: sobre a circulação, produção e reconhecimento}

A primeira inferência é sobre a validade do objeto social (a exposição) como objeto epistemológico para análise da midiatização. Isso já foi feito na introdução deste artigo. Essa validade só pode ser epistemológica, ou seja, como hipótese quase filosófica sobre o que é midiatização (a midiatização como perspectiva de observação metamidiática, como sugere Gomes [2017]).

Nessa perspectiva epistemológica, a pesquisa sobre a circulação é uma mediação central, de aproximação à análise dos processos midiáticos. Nesse encaminhamento, a perspectiva da pesquisa é clara: a circulação operacionaliza a critica ao estruturalismo. $O$ estruturalismo teria como objeto central as estruturas ou sistemas de produção. Não se trata, entretanto, de negar a importância da compreensão das estruturas ou dos sistemas de produção (validando, de certa forma, a importância de continuidade das contribuições que visam compreender as lógicas de produção - na perspectiva diretamente semiótica, sistêmica ou ideológica). Sem negar a importância desse momento na análise, a circulação quer avançar: pensar as relações entre a produção e o que pode ser caracterizado, genericamente, como recepção (termo amplo com o qual designamos os acessos, consumo, usos, utilizações, práticas e apropriações sociais à jusante).

A análise da produção, na perspectiva de apreensão das lógicas, pode recorrer a diversas referências. No caso da investigação sobre a exposição, as referências são a semiótica, mas podem, em nossa compreensão, recorrer ao discurso, à ideologia e, inclusive, à análise de sistemas de produção (especialmente, agora, na "era dos algoritmos). A articulação dessas diversas referências nos parece produtiva. Analisar a circulação sem apreender essas lógicas é, na perspectiva que propomos, precário. Porém, pode-se afirmar que muitos estudos sobre a midiatização ficam retidos nesse momento (análise dos sistemas de produção - utilizando recursos oferecidos pela semiótica, critica ideológica ou sistêmica). Trata-se, nesses casos, de crítica às formas de materialização da experiência mental de individuos, atores, instituições etc. Esse momento é essencial, mas é insuficiente se o proposto é a investigação da midiatização na perspectiva da circulação. Para isso, além da análise das lógicas de produção, é essencial o estudo das formas de reconhecimento.

\section{Analogias (ampliando-se inferências a partir do caso)}

Em termos metodológicos, a questão do reconhecimento se refere a diversos "niveis" - todos importantes para se evitar a abstração de processos envolvidos na "recepção". Todos devem ser analisados, e nos convocam a pensar a circulação como uma epistemologia das relações concretas a serem pensadas também na esfera do reconhecimento.

Esse estudo sobre a exposição nos sugere buscar inferências sobre a relação do "receptor" com o território institucionalizado (o "nome" do espaço e tempo visitado) - como lugar de acesso, consumo, uso e práticas em relação aos objetos culturais. Esse tópico nos remete à importância de considerar, no consumo de objetos culturais, as relações do imaginário com o "canal" frequentado, em seu tempo e espaço de ocorrência. Por analogia, essa relação com o canal pode se dar com uma rádio, uma televisão, um jornal, um lugar de exposição, mas também outros meios não tão canônicos (um restaurante, um ônibus, um metrô, uma clínica de fisioterapia etc.). Ou, atualmente, a visitação aos espaços agenciados por camadas de algoritmos (um blogue, o Facebook, o Instagram etc.). Considera-se, aqui, o nome do meio como uma mediação importante a considerar na esfera dos acessos, utilizações, usos, práticas e apropriações. Esses processos se diferenciam. Não é a mesma coisa quando se referem a Globo, Netflix, WhatsApp etc. Trata-se, aí, de pensar a relação acionada pelo meio. Retirar um conteúdo do meio em que se insere é uma operação de abstração que é questionada. O "conteúdo" deve ser localizado, não por um contexto, mas metodologicamente, se a perspectiva epistemológica de análise é a circulação.

O segundo movimento metodológico no es- 
tudo do reconhecimento é a relação de acessos, usos, práticas e apropriações com um programa específico no âmbito do canal escolhido (acima referido). Muitas vezes é o destaque nas pesquisas em recepção (relação com a telenovela, o telejornal etc.). Nem todos os meios, em seus tempos e espaços, oferecem "programas" especificados. Adotando a perspectiva epistemológica sobre os objetos da midiatização, uma academia, por exemplo, pode ou não oferecer programas especificados (aparelhos, natação, jumps etc.). Subentende-se que essa especificação produza formas de interação diferenciadas. O mesmo vale para o rádio, televisão, jornal, cinema. Uma escolha por um canal (referida no parágrafo anterior) pode ter como objeto alguns programas especificos (um telejornal, uma telenovela, um seriado etc.), conforme estratégias especificas (apreciação, critica, entretenimento etc.).

Interessante especificação deve ser feita aqui. Posso "entrar" no canal conforme uma programação (mesmo quando essa, sendo indexada, como na Netflix, seja diferida no tempo), ou ingressar no canal em busca de "nada", acompanhando a programação em curso ou buscando, no indexador, um programa. Ou seja, não é a mesma coisa se a "visita" decorre de uma escolha conforme a "grade de programação", ou se, na ausência desta grade antecipada, se fez presença por um acaso (a pessoa passa no local e decide visitar a exposição; preencher tempo livre etc.). Essa diferenciação é importante, em nossa perspectiva, para a compreensão dos niveis de relação que os receptores têm com os meios em estudo - inclusive se esses meios se constituem em dispositivos mentais relativamente estabilizados. Imagine-se, por exemplo, essa diferenciação quando se observam visitas ao Facebook, ao WhatsApp, Instagram etc., mas também as visitas realizadas em um bar, na academia etc.

A consideração dos aspectos anteriores (acesso ao "canal" e ao "programa' nesse canal) não é apenas contexto do contato com os objetos signos em suas materialidades mais especificas. Essas "escolhas" ressignificam o que aqui designamos como terceiro nivel para se pensar o reconhecimento: percepções de contato e percurso no âmbito do tempo, do espaço e dos signos disponiveis no canal, no programa expectado ou em visitações flutuantes (como um flâneur), que são materiais para novas inferências do pesquisador sobre o reconhecimento. A entrevista é o momento em que o receptor revela, em parte, as interações entre meio-signo, em seus tempos e espaços, e a sua experiência mental quando em contato com os mesmos, o que é retido em termos de memória relacional, nominal, metafórica (como se diz) e metapórica (como sente o que faz), e diagramática (quando convidado a desenhar o percurso realizado).

Outro importante detalhe metodológico: questiona-se a validade dos videos para a retomada das questões já encaminhadas em formato de diagramas. Pelo contrário, parece que, antes das entrevistas, as gravações em video ocupam um espaço central apenas na definição de diferenciações de leituras, demarcando inclusive em termos métricos os individuos a serem entrevistados (7 "formigas"; 6 "peixes"; 4 "borboletas"; 4 "gafanhotos"; 4 "mistos"). É importante destacar que os investigadores não focam nos quatro casos que consideramos mistos. Conservam, para as suas reflexões, os casos "puros" (formigas, gafanhotos, borboletas e peixes).

Ou seja, as imagens são centrais em termos metodológicos, tendo mais importância do que as entrevistas. Funcionam como "prova" material de percursos. As entrevistas apenas chancelam o que se observa, permitindo inferências adicionais, ampliativas. Esse movimento coloca questões complexas à investigação do reconhecimento nas redes. Como etnografar isso?

Os diagramas finais, por sua vez, permitem uma diferenciação na perspectiva do método. Já não se trata de verificação da validade de hipóteses de partida, mas de hipóteses relativas ao caso investigado. Singulariza não só a fecundidade da teoria em construção (a midiatização, considerando-se o objeto em estudo), mas também sua operacionalização (a circulação), mas ponderadas pela singularidade do objeto estudado (o caso). O caso, nesse sentido, enriquece, pela investigação empírica, as perspectivas epistemológicas sugeridas (a midiatização e a circulação). 


\section{Questionamentos}

Muitas questões e metainferências derivam desse estudo que condensamos aqui.

O conceito de midiatização é metamidiático, convergindo com Gomes (2017). Refere-se a um processo antropológico maior. Mas, na pesquisa empírica, é um concreto que pode se manifestar na análise da circulação, como referência para a construção de casos de investigação que permitem inclusive enriquecer as referências epistemológicas sobre a midiatização, como inteligibilidade de análise entre os processos midiáticos e os processos sociais, históricos ou atuais. A midiatização - ou semiose midiatizada -, entretanto, não abrange todos os sentidos sociais e naturais em curso. Há um universo de sentido que não se materializa em signos. Isso nos convoca a refletir sobre os limites históricos e sociais da midiatização, como objeto epistemológico, empírico, histórico e social de investigação.

A circulação, porém, na medida em que se refere às materialidades, não sofre essa interposição. Uma discussão que permanece: é possivel falar em sistemas ou lógicas de recepção assim como é possivel analisar na esfera da produção? Questões que permanecem: os usos são estruturados? Se esses são estruturados, sistêmicos e lógicos, é possivel falarmos em habitus?

O conceito de habitus é correlato a uma prática social. Lahire (2002) acentua isso, diferenciando o habitus dos usos - em que o primeiro é o que se estabiliza em práticas sociais compartilhadas e os segundos são imprevisiveis, efêmeros. Essas práticas têm como pressuposto esquemas de percepção, intuição, apreciação e produção de sentidos socialmente reconhecidos entre os participantes do concerto interacional. As investigações de Bourdieu estabelecem relações entre o habitus e posições nos campos sociais (relativas à posse de capitais culturais, econômicos e políticos). Isso se relaciona à temática aqui abordada enquanto questionamentos. A primeira mediação entre meios, usos sociais, circuitos e circulação é o habitus, quando se acentua a perspectiva metodológica etnográfica. Somente em um segundo momento é possivel relacionar habitus e campos sociais - em que a diversidade de práticas é posicionada enquanto capitais. Verón, ao se dedicar ao microcosmo do uso do meio exposição, identifica usos - que podem ser práticas, mas isso dependeria de outros casos investigados. Essas teriam que ser relacionadas aos capitais, para que então pudéssemos ver em suas pesquisas uma resposta positiva às perspectivas socioantropológicas de Bourdieu.

Portanto, isso tudo nos remete à reflexão acerca dos campos sociais, aos capitais culturais, econômicos e políticos dos usuários. Essas dimensões são informadas por Verón, mas não são cruzadas com os dados. Mas esses cruzamentos deveriam passar pelo habitus, sob pena de se perderem em relações entre produção, reconhecimento e contextos sociais. O que a teoria crítica dos campos vai acentuar é que ali, no microcosmo das interações, vão se realizar, se condensar, relações sociais mais amplas, contextualizadas pelos capitais e pelos habitus. A aceitação dessas relações, no microcosmo, é reprodutiva de relações de poder simbólico. Mas a questão adicional é outra: como a midiatização, processo em que as interações e a comunicação estão interpostas pelos meios, transforma essas relações de poder, ao mesmo tempo que as reproduz?

Aqui, os processos midiáticos, quando analisados pelas epistemologias da midiatização, enfocadas pela observação sobre a circulação, remetem à questão do poder simbólico que se constitui nesse processo. Essas relações podem ser abordadas especificamente em sistemas de produção e acessos, usos, práticas e apropriações de um meio em especifico? É necessário pesquisar analogias entre esses processos diversos, considerando mutações dos meios, ou mutações dos atores e contextos dos mesmos meios?

Pode se questionar, aí, que ambiência (metamidiática) e ambiente (especificado, conforme experiências sociais singulares com os meios) emergem desses processos. Ou seja, que simbólica nasce nesses processos, em termos de novas economias (da cultura, da política e da economia em termos estritos), éticas e renovações estéticas. Essa é outra interlocução essencial entre os processos de 
circulação, de reconhecimento, e midiatização. Aproxima-se mais das interlocuções com as teorias críticas na linhagem frankfurtiana e com o campo psi. Estamos fazendo isso também. Em próximos artigos.

É nesse jogo metodológico que poderemos fazer inferências diferenciais sobre tendências e transformações das relações sociais, das relações de poder entre as classes, etc. Isso será investigado, enquanto hipótese, em artigo futuro - em que vamos explorar interfaces entre a perspectiva de Verón e a de Bourdieu.

Nesse processo, as analogias, quando consideram a mutação dos meios, parecem ser mais produtivas, especialmente quando isso ocorre de forma quase cotidiana. A mutação dos meios expressa, nesse sentido, não só a materialização da experiência mental da espécie, mas também dos acessos, usos, práticas e apropriações tentativas. Estudar essas relações, considerando a circulação, é a grande contribuição dos estudos de midiatização. A mediação entre o micro e o macro é o habitus. Mas o habitus não se apreenderia no micro, pois consideraria um conjunto de experimentações sociais análogas e homólogas para ser inferido. Esse só pode ser inferido a partir de sucessivos casos, os quais, por analogias e homologias, sugerimos, podemos inferir esse lugar como referência para investigações sobre os processos midiáticos, na perspectiva da midiatização, em suas relações com os processos sociais.

Finalmente, é importante questionar a dimensão comunicacional quando nos referimos à circulação. A comunicação aí não é aquela que ocorre entre os interagentes. Refere-se à comunicação mediada, entre produtores de uma temporalidade e espacialidade (a exposição), estruturada enquanto lógicas, passiveis de análise inclusive crítica, e os usuários desse espaço e tempo. Entre eles, não há conversação, embora possamos falar em negociação, em ideologia (ou perversão ou conversões), que talvez convoquem instituições e organizações a atualizar suas lógicas, estruturas e sistemas de produção.

\section{Referências}

BOURDIEU, Pierre. Les rites comme actes d'institution. Actes de la recherche en sciences sociales, [S. l.], V. 43, p. 58-63, jun. 1982. Disponivel em: https://www.persee. fr/doc/arss_0335-5322_1982_num_43_1_2159. Acesso em: 01 dez. 2019. https://doi.org/10.3406/arss.1982.2159

BOURDIEU, Pierre; DARBEL, Alain. L'amour de l'art: Les musées et leur public. Paris: Editions de Minuit, 1966.

BOURDIEU, Pierre. La distinción: criterios y bases sociales del gusto. 2. ed. Madrid: Taurus, 2000.

FAUSTO NETO, Antonio. Fragmentos de uma "analítica" da midiatização. Matrizes, São Paulo, v. 1, p. 89-105, 2008. Disponivel em: https://www.revistas.usp.br/ matrizes/article/view/38194. Acesso em: 01 dez. 2019. https://doi.org/10.11606/issn.1982-8160.v1i2p8.9-105

FERREIRA, Jairo. Uma abordagem triádica dos dispositivos midiáticos. Líbero (FACASPER), São Paulo, v. 1, p. 1-15, 2006.

FERREIRA, Jairo. Midiatização: dispositivos, processos sociais e de comunicação. E-Compós, Brasília, v. 10, p. 1-15, 2007. https://doi.org/10.30962/ec.v10io.196

FERREIRA, Jairo. O caso como referência do método: possibilidade de integração dialética do silogismo para pensar a pesquisa empirica em comunicação. InTexto, Porto Alegre, v. 27, p. 161-172, 2012.

FERREIRA, Jairo. Uncertainty and indeterminacy in Brazilian social and media formation: references to think of the problem of recognition in the public space. ESSACHESS - Journal for Communication Studies, IS. l.], v. 10, p. 269-287, 2017.

FERREIRA, Jairo. Meios, dispositivos e médium: genealogia e prospecções na perspectiva da midiatização. In: FERREIRA, Jairo; ROSA, Ana Paula; BRAGA, José Luiz; FAUSTO NETO, Antônio; GOMES, Pedro Gilberto. (org.). Entre o que se diz e o que se pensa: onde está a midiatização?. Santa Maria: FACOS-UFSM, 2018. V. 1. p. 283-298.

GOMES, Pedro Gilberto. Dos meios à midiatização um conceito em evolução. São Leopoldo: Editora Unisinos, 2017.

LACEY, Hugh. Pluralismo metodológico, incomensurabilidade e o status científico do conhecimento tradicional. Scientiæ Studia, São Paulo, v. 10, n. 3, p. 425-53, 2012. Disponivel em: http://www.scielo.br/ scielo. php? pid $=$ S1678 $=31662012000300002-\&$ script sci_arttext\&tlng=pt. Acesso em: 01 dez. 2019. https:// doi.org/10.1590/S1678-31662012000300002

LAHIRE, Bernard. O homem plural. Petrópolis: Vozes, 2002. Disponivel em: https://pt.slideshare.net/lolanascimento315/homem-pluralos determinantesdaacao. Acesso em: 01 dez. 2019.

MARIANI-ROUSSET, Sophie. Espace public et publics d'expositions: Les parcours: une affaire à suivre. In: GROSJEAN, Michèle; THIBAUD, Jean Paul (org.). L'espace urbain en méthodes. Marseille: Parenthèses, 2008. Disponivel em : http://www.siclone.org/articles/ espace-public.pdf. Acesso em: 01 dez. 2019. 
MARX, Karl. Grundrisse: manuscritos econômicos de 1857-1858. São Paulo: Boitempo, 2011.

MIĖGE, Bernard; FERREIRA, Jairo; FAUSTO NETO, Antonio; AQUINO BITTENCOURT, Maria Clara J. (org.). Operações de midiatização: das máscaras da convergência às críticas ao tecno-determinismo. Santa Maria: FACOS-UFSM, 2016. Disponivel em : https://WWW. midiaticom.org/operacoes-de-midiatizacao-miege/. Acesso em: 01 dez. 2019

HJARVARD, Stig. Da Mediação à Midiatização: a institucionalização das novas mídias. Revista Parágrafo, São Paulo, v. 3. n. 2, p. 51-62, 2015. Disponivel em: http:// revistaseletronicas.fiamfaam.br/index.php/recicofi/ article/view/331. Acesso em: 01 dez. 2019.

VERÓN, Eliseo. La semiosis social 2: Ideas, momentos, interpretantes. Buenos Aires: Paidós, Planeta, 2013.

VERÓN, Eliseo; LEVASSEUR, Martine. Ethnographie de l'exposition: l'espace, le corps et le sens. Paris: Centre Georges Pompidou, 1989.

VERÓN, Eliseo. Teoria da midiatização: uma perspectiva semioantropológica e algumas de suas consequências. Matrizes, São Paulo, v. 8, n. 1, p. 13-19, jan./jun. 2014. Disponivel em: https://www.revistas.usp.br/matrizes/ article/view/82928. Acesso em: 01 dez. 2019.

\section{Jairo Getúlio Ferreira}

Doutor em Informática na Educação pela Universidade Federal do Rio Grande do Sul (UFRGS), em Porto Alegre, Brasil; Mestre em Sociologia pela Universidade Federal do Rio Grande do Sul (UFRGS), em Porto Alegre, Brasil; pós-doutor em comunicação pela Universidade Nacional de Rosário (UNR), em Rosário, Santa Fé, Argentina; professor titular do Programa de Pós-Graduação em Ciências da Comunicação da Universidade do Vale do Rio dos Sinos, Porto Alegre, RS, Brasil.

\section{Endereço para correspondência}

Jairo Getúlio Ferreira

Universidade do Vale do Rio dos Sinos

Programa de Pós-Graduação em Ciências da Comunicação

Avenida Unisinos, 950

Cristo Rei, 93022750

São Leopoldo, RS, Brasil 